\title{
Adsorption characteristics of acetaldehyde on activated carbons prepared from corn-based biomass precursor
}

\author{
Kwang-Hyun Park ${ }^{\mathrm{a},+}$, Wang-Geun Shim ${ }^{\mathrm{a},+}$, H.K. Shon ${ }^{\mathrm{b}}$, Sang-Guk Lee ${ }^{\mathrm{a}}$, \\ Huu-Hao Ngo ${ }^{\mathrm{b}}$, S. Vigneswaran ${ }^{\mathrm{b}}$, Hee Moon ${ }^{\mathrm{a}, *}$
}

${ }^{a}$ Center for Functional Nano Fine Chemicals and Faculty of Applied Chemical Engineering, Chonnam National University, Gwangju 500-757

${ }^{\mathrm{b}}$ Faculty of Engineering, University of Technology, Sydney (UTS),

P.O. Box 123, Broadway, NSW 2007, Australia,

${ }^{+}$These authors are equally contributed this work.

*Corresponding author

Email address: $\underline{\text { hmoon@jnu.ac.kr, }}$

Fax number: +82-62-530-1899 


\section{Abstract}

Activated carbons (ACs) having different physical and chemical properties were prepared from biomass precursor using corn grain. Adsorption characteristics of acetaldehyde on corn-based activated carbons (R-1/2 and R-1/4) and commerciallyavailable wood-based activated carbon (WAC) were assessed at room temperature using gas chromatograph (GC). The effects of acetaldehyde adsorption on ACs were investigated in terms of textural properties, energetic heterogeneity, and surface chemistries. In addition, considering the effect of the existed oxygen containing groups on the surface of ACs on acetaldehyde adsorption, the adsorption properties of water vapor were also evaluated in terms of the effect of the existed oxygen containing groups on the surface of ACs on acetaldehyde adsorption,. The results suggested that the influences of pore size distribution (below $8 \AA$ ) and energetic heterogeneity of ACs on acetaldehyde adsorption were highly predominant rather than specific surface area and surface chemistry. The experimentnal results of acetaldehyde adsorption were well correlated by the Langmuir equation. Besides, the pseudo second equation was well represented kinetic information of acetaldehyde adsorption.

Keywords: Corn grain; Acetaldehyde; Activated carbon; Water vapor, Adsorption 


\section{Introduction}

With growing concerns of an indoor decoration the concentration of aldehyde compounds accumulated in indoor air has been one of a major issues and needs to be removed. Especially, acetaldehyde, which is one of main aldehyde compounds, is recognized as a toxic material. It is usually emitted by decorated materials, cigarette smoke, paint, polymerized plate, binder, etc. [1]. The excessive exposure of the high acetaldehyde concentration to body causes serious symptoms such as headache, nausea, DNA damage, and abnormal muscle development [2].

There are several methods to remove acetaldehyde compounds in air such as oxidation, absorption/adsorption, condensation and biofiltration. Among them, adsorption process has been known as the most effective method to remove acetaldehyde because of its high selectivity, process simplicity, and safety [3].

Activated carbon (AC), which has been widely used in the adsorption process, is one of the most potential adsorbents due to the proper properties such as large surface area, broad pore size distribution, microporocity, and thermal stability. In general, the ACs were prepared from various precursors such as biomasses, coals, resins, synthetic polymers, petroleum coke, phenolic resins, peat, etc.

Biomass precursors have been used for preparation of highly porous ACs owing to the properties of high carbon and low inorganic contents, relatively cheaper, and an abundant amount [4-6]. There are numerous biomass source such as wheat, misconstrues, pinecone, coconut shell, cotton residues, almond shells, cotton, olive stones, cherry stones, corn straw, corn hulls, corn stover, corn cob, rice husk, and rice hull. These sources have been utilized in various fields [7].

In this work, the main objectives of this study were to prepare novel ACs 
having different physical properties and surface chemistry from corn grains and to assess the adsorption capacities of acetaldehyde compared to commercial AC.

\section{Experimental}

\subsection{AC characterization}

Three ACs having the different physical and chemical properties were selected in this study. Two samples were prepared from corn grain. The preparation procedures of the ACs were described elsewhere $[3,8,9]$. The ACs were denoted as R-1/2 and R1/4, respectively. Another sample, which is the wood based activated carbon (WAC), was chosen for comparison of adsorption capacity of acetaldehyde and water vapor.

The physical properties of all samples were determined by nitrogen adsorption/desorption isotherms at $77 \mathrm{~K}$ (Micrometrics ASAP 2020). The specific surface area was calculated by the basis of BET theory in the relative pressure range of 0.01-0.05. The total pore volume $\left(\mathrm{V}_{\mathrm{T}}\right)$ was calculated from the nitrogen adsorption data at a relative pressure range of 0.99 and the total pore width was measured using the following equation $\left(4 \mathrm{~V}_{\mathrm{T}} / \mathrm{S}_{\mathrm{BET}}\right)$. The Dubinin-Radushkevich (DR) equation was used for micropore volume $\left(\mathrm{V}_{\mathrm{DR}}\right)$. The pore size distribution (PSD) and pore volume of samples were evaluated by the density functional theory (DFT) $[3,8,9]$.

The surface functional groups of all samples were examined using the Fourier transform infrared spectroscopy (FT-IR, BIO-RAD, FTS-175C) and the X-ray photoelectric spectroscopy (XPS, Multi lab 2000/Thermo electron corporation, England). In the case of FT-IR analysis the activated carbons were mixed with $\mathrm{KBr}$ at a mass ratio of $\mathrm{AC} / \mathrm{KBr}(1: 30)$ to form into pellet $[10,11]$. 


\subsection{Water vapor adsorption}

Adsorption experiments of water vapor on all samples were carried out in an isolated chamber which kept at $50 \%$ relative humidity at $30^{\circ} \mathrm{C}$. About $50 \mathrm{mg}$ of activated carbons was put onto weight machine (AR2140, OHAUS/US) in the isolated chamber, respectively. Then, the weight change was recorded as a function of time. When the weight change of a sample was maintained within the range of about \pm 0.1 mg, the adsorption equilibrium state was assumed.

\subsection{Acetaldehyde adsorption using gas chromatograph}

Adsorption of acetaldehyde (Stem Supply, SA, Australia) was studied using a cuboids stainless (Top-face glass) airtight reactor with a total volume of $3.8 \mathrm{~L}$. The reactor had three rubber openings; the first was used for the injection of acetaldehyde, the second connected to an air pump to ensure mixing of air inside the reactor and the third as sampling aperture connected to a gas chromatograph (GC) / flame ionization detector (FID) (hp5890 series II, Wilmington, USA) for measuring acetaldehyde concentration variations. The reaction took place at room temperature of $25^{\circ} \mathrm{C}$ around $60 \mathrm{~min}$.

About $0.5 \mathrm{~g}$ of activated carbon was sprinkled in a glass Petri-dish $(9 \mathrm{~cm}$ of diameter) in the centre of the reactor. After closing the reactor door, the adsorption capacities on all samples were measured. With varying the initial acetaldehyde concentration acetaldehyde was injected through the injection cavity using an airtight syringe. The concentration of acetaldehyde was recorded at fixed 3.8 min intervals.

\section{Results and discussion}




\subsection{Physical and chemical properties of ACs}

The textual properties and surface functional groups of AC were highly influenced on organic compound adsorption. The textural properties of the ACs were determined by $\mathrm{N}_{2}$ adsorption/desorption isotherms at $77 \mathrm{~K}$ and were given in Table 1. The DFT equation was used to investigate the effect of PSDs of ACs on acetaldehyde adsorption. R-1/4, which was one of the ACs prepared from corn grain, possessed the values of largest specific surface area and total pore volume. In the contrast of the R-1/4, R-1/2 showed the relatively narrow pore size distribution, mostly in the range of 3-8 $\AA$, as shown in Fig. 1.

The surface functional groups of ACs, especially the surface oxygen functional groups, are measured by FT-IR and XPS. The FT-IR spectra have been used to identify the functionality of AC qualitatively. XPS has been used to assess the quantitative atomic compositions. The FT-IR spectra of ACs were analyzed in the range of 4000$1000 \mathrm{~cm}^{-1}$ (Fig. 2). All the ACs appeared a couple of absorption peaks at 1575 and 1375 $\mathrm{cm}^{-1}$. The absorption peak at $1375 \mathrm{~cm}^{-1}$ was considered as the methyl group [10] and the other at $1575 \mathrm{~cm}^{-1}$ could be represented to the C-C stretching vibrations of polyaromatic $\mathrm{C}=\mathrm{C}[10,11]$. However, the FT-IR characteristic peaks of all the ACs showed the weak intensities due to natural black body of AC. Therefore, the XPS was used for examining the surface binding state and elemental speciation in detail. The XPS spectra had two distinct peaks considered as carbon and oxygen. The C1s spectra of all the samples are represented in Fig. 3. The elemental surface compositions of graphitic carbon (285 eV), phenolic (286.7 eV), carbonyl (288.4 eV), carboxylic (289.7 eV), and carbonate group (290.7 eV) are listed in Table 2. In the case of ACs prepared from corn grain the percentage occupied by the oxygen containing groups on the AC surface increased with 
the increasing mass ratio between corn grain char and $\mathrm{KOH}$. It was also observed that the percentage of the oxygen containing groups of the R-1/4 was similar with that of the WAC.

\subsection{Acetaldehyde adsorption}

The adsorption capacities of acetaldehyde on ACs were assessed using gas chromatograph at room temperature. The adsorption equilibrium isotherms of them were shown in Fig. 4. The R-1/2 showed the highest adsorption capacity compared to the R-1/4 and the WAC. According to the previous work, the adsorption capacity of acetaldehyde on AC was strongly dependent on various factors such as the specific surface area, pore structure, pore size distribution, energetic heterogeneity between the adsorbent and the adsorbate, and oxygen-containing groups on AC [4-6, 12, 13]. Thus, the adsorption property correlations among the textual property and the surface chemistry as well as the energetic heterogeneity on acetaldehyde adsorption were examined to find out the optimum adsorption condition.

On adsorption of small molecular VOCs, especially acetaldehyde (3.8 $\sigma$ ), the adsorption capacity on AC depends on various properties such as specific surface area, pore size distribution, surface energetic heterogeneity, and oxygen containing groups on the surface of AC. Also, it has been known that the acetaldehyde adsorption capacity increased with the increasing specific surface area and pore volume of AC $[5,6]$. In this study, a linear relationship between the specific surface area and the capability of AC on acetaldehyde adsorption was not observed in Table 3. On the other hand, the acetaldehyde adsorption capacity of AC was enhanced with the increment of amount of micropore pore volume (below $8 \AA$ ). These results indicated that the adsorption capacity 
of acetaldehyde on the AC was subjected to a correlation between the molecular size of acetaldehyde and the pore size of AC. Therefore, this suggests that the pore size distribution (below $8 \AA$ ) of the ACs was strongly predominant on acetaldehyde adsorption.

The existing oxygen functional groups on the surface of AC usually determine the charge of the surface, hydrophobicity, and the electronic density of the graphene layers [4-6]. In general, these oxygen containing groups on the surface of AC interacted with acetaldehyde [14]. Thus, the adsorption capacity of acetaldehyde was influenced by the existed amounts of oxygen groups on the surface of ACs $[5,6]$. However, the R1/2 which was observed with the highest adsorption capacity mostly consisted of graphitic carbon (about $80 \%$ ). Interestingly, the R-1/4 having the similar percentage of oxygen containing group with the WAC was observed with the parallel adsorption capacity with the WAC. Therefore, it is again confirmed from the correlation studies that the acetaldehyde adsorption on the ACs was mainly influenced by the pore size distributions (below $8 \AA$ ).

The correlation study between the acetaldehyde adsorption capacity and the surface energetic heterogeneity of ACs was investigated. The energetic heterogeneities of solid surface can be described by adsorption energy distribution (AED). The AED were calculated by the following integral equation $[15,16]$.

$$
\theta(p)=\int_{\Delta} \theta_{1}(p, U) \cdot F(U) d U
$$

where $\theta(p)$ is the experimental adsorption isotherm data, $\Delta$ the integration region, $U$ the adsorption energy, $F(U)$ the energy distribution, and $F(U) d U$ denotes the fraction of 
the surface with adsorption energies between $U$ and $U+d U . \theta_{1}(p, U)$ is the local adsorption isotherm.

According to the current works, the Fowler-Guggenheim (F-G) local adsorption equation has been used to assess the localized monolayer adsorption on single component in gas phase. The F-G equation can be described as the following integral fundamental expression.

$$
\theta_{1}(P, U)=\frac{b p \exp \left(\frac{z w \theta}{k T}\right)}{1+b p \exp \left(\frac{z w \theta}{k T}\right)} \quad b=b_{0}(T) \exp \left(\frac{U}{k T}\right)
$$

where $T$ is the absolute temperature, $p$ the equilibrium pressure, $z$ the number of closest adjacent molecules in the monolayer, $w$ the interaction energy between the two nearest neighboring molecules, $k$ the Boltzmann constant, $b$ the Langmuir constant, and the preexponential factor $b_{0}(T)$ can be calculated from the partition function for an isolated molecule.

The calculated AEDs of acetaldehyde on all the ACs were given in Fig 5. The relatively energetic heterogeneity can be assessed by the AEDs of each AC [17]. Furthermore, it has been known that the peak of AED shifted towards the higher adsorption energy is attributed to the development of the small microporocity of AC [18]. In this work, it was found that the peaks of AED of the ACs showed the higher adsorption energy and the maximum peak height of AEDs on ACs was investigated in the order of $\mathrm{R}-1 / 2>\mathrm{WAC}>\mathrm{R}-1 / 4$. These results were in the agreement with the order of adsorption capacities of acetaldehyde on ACs. Hence, the AED results indicated that the 
relatively higher adsorption energy and maximum peak height of AC on acetaldehyde adsorption was highly important parameter to attain the higher adsorption capacity, similar to textural characterization.

\subsection{Water vapor adsorption}

As mentioned in the previous section, the R-1/4 which has the largest specific surface area and highest pore volume, was observed the similar adsorption capacity with the WAC. The water vapor adsorption on the surface of AC is correlated with hydrophilic functional groups [19]. Thus, considering the effect of oxygen containing groups on the surface of the ACs, the water vapor adsorption property was assessed as a function of time. The adsorption isotherms of water vapor were given in Fig. 6. It was found that the order of adsorption capacity of water vapor on ACs was the same as with the order of acetaldehyde adsorption capacity. According to the previously reported manuscript, the high adsorption amount of water vapor on the carbon sample of the lower surface area can be explained by the higher concentration of surface oxygen groups on the surface of these carbon samples compared to the activated carbon samples of the higher surface area investigated [20]. As listed in Table 2, the percentage of the existing oxygen groups on the surface of R-1/4 and WAC was comparable. Therefore, these results could well explain the correlation for the adsorption property between the R-1/4 and WAC.

In these studies, the reasonable effects of the oxygen groups existing on the surface of ACs were not found on acetaldehyde and water vapor adsorption. On the other hand, it was confirmed that the adsorption capacity of acetaldehyde and water vapor on the ACs predominantly relied on the pore size distribution (below $8 \AA$ ) of AC, 
especially small molecular adsorption.

\subsection{Adsorption Isotherm}

The Langmuir and Freundlich isotherm models were employed to describe the interaction between the acetaldehyde and ACs. The Langmuir equation was given as follows:

$$
q_{e}=\frac{q_{m} \cdot b \cdot C_{e}}{1+b \cdot C_{e}}
$$

where $q_{m}$ and $b$ are Langmuir isotherm parameters, and $q_{e}$ the equilibrium adsorbed amount, and $C_{e}$ the concentration of adsorbate at equilibrium condition. The calculated Langmuir isotherm model parameters are listed in Table 3. Evaluating the suitability of Langmuir equation, the correlation coefficient $\left(R^{2}\right)$ was estimated based on plotting $C_{e} / q_{e}$ versus $C_{e}$.

The Freundlich isotherm equation was considered as an empirical equation. The Freundlich isotherm equation is given as follows:

$$
q_{e}=K_{F r} \cdot C_{e}^{1 / n}
$$

where $q_{e}$ is the amounts adsorbed, and $C_{e}$ the concentration of adsorbate at equilibrium. $K_{F r}$ and $\mathrm{n}$ are Freundlich isotherm parameters. In addition, the correlation coefficient $\left(R^{2}\right)$ was derived by plotting the correlations between $\ln \left(q_{e}\right)$ versus $\ln \left(C_{e}\right)$ and experimental data. 
The Freundlich isotherm parameters were listed in Table 3 along with their correlation coefficient $\left(R^{2}\right)$ values. The R-1/2 showed the highest value of Langmuir parameter $(b)$ and its correlation coefficient $\left(R^{2}\right)$ was closely to 1 . Also, it was found that the values of Langmuir parameters $\left(b, q_{e}\right)$ of ACs were in agreement with the order of adsorption capacity of acetaldehyde (R-1/2>WAC $>\mathrm{R}-1 / 4)$. As a result, the Langmuir isotherm model was more suitable to explicate the correlation of experimental results.

\subsection{Adsorption kinetics}

The adsorption kinetics of acetaldehyde on ACs were assessed with varying the initial concentrations of acetaldehyde at room temperature. In this study, the empirical equations (pseudo first order and second order equation) were used for evaluating the the correlation between the adsorbed amount and the required time. The pseudo firstorder (5) and second-order (6) equations are described as following mathematical expressions:

$$
\begin{aligned}
& \frac{d q_{t}}{d t}=k_{f} \cdot\left(q_{e}-q_{t}\right) \\
& \frac{d q_{t}}{d t}=k_{s} \cdot\left(q_{e}-q_{t}\right)^{2}
\end{aligned}
$$

where $q_{e}$ is the maximum quantity of acetaldhyde adsorbed at equilibrium, and $q_{t}$ the adsorbed quantity of acetaldhyde. $k_{f}$ and $k_{s}$ the kinetic constant of pseudo first-order and second-order equation, respectively. The suitability studies of the equations were conducted through the corresponding correlation coefficient $\left(\mathrm{R}^{2}\right)$. 
The parameters derived by the pseudo first-order and the pseudo second-order equation are given in Table 4. It was found that the adsorption kinetics of acetaldehyde on ACs were well illustrated by the pseudo second order equation compared to pseudo first order equation. Also, the values of $q_{e}$ calculated from the pseudo second-order equation were consistent with experimental data and the values of $R^{2}$ were in between 0.99-1. Accordingly, the pseudo second-order equation was highly suitable to explain the correlation between experiment data and the adsorption kinetics of acetaldehyde on all the ACs, as shown in Fig. 7.

\section{Conclusion}

The ACs (R-1/2 and R-1/4) having two different textual and chemical properties were prepared from corn grain and the adsorption capacities of acetaldehyde were assessed using gas chromatograph at room temperature. The R-1/2 which

possessed various properties such as the pore size distribution (below $8 \AA$ ), the peak of highest adsorption energy, and the peak of the highest adsorption energy height, showed the highest adsorption capacity of acetaldehyde. More detail, the correlation between the specific surface area and the density of surface oxygen groups of the R-1/4 and the WAC through water vapor adsorption were investigated due to the similar adsorption capacity of acetaldehyde. Especially, the adsorption equilibrium of ACs was evaluated by Langmuir and Freundlich equations. The results were well correlated by the Langmuir equation. In addition, the adsorption kinetics were assessed by pseudo first and second order equations. The pseudo second equation was well explained the adsorption kinetic of acetaldehyde. 


\section{Reference}

[1] World Health Organization Regional Office for Europe, Air Quality Guideline. Second ed., Copengagen, 2001.

[2] Manahan, S. E. Environmental Chemistry, 6 ${ }^{\text {th }}$ ed.; CRC Press: Baca Raton., FL, 1994.

[3] K. H. Park, M. S. Balathanigaimani, W. G. Shim, J. W. Lee, H. Moon, Micropor. Mesopor. Mater., Impress.

[4] S. Kumagai, K. Sasaki, Y. Shimizu, K. Takeda, Sep. Purif. Technol., 61 (2008) 398

[5] Yehya El-Sayed, Teresa J, Bandosz, Langmuir, 18 (2002) 3213

[6] Yehya El-Sayed, Teresa J, Bandosz, J. Colloid Interf. Sci. 242 (2001) 44

[7] O. Ioannidou, and A. Zabaniotou, Renew, Sustain. Energy Rev., 11 (2007) 1966

[8] M.S. Balathanigaimani, W. G. Shim, K. H. Park, J. W. Lee, H. Moon, Micropor. Mesopor. Mat., 118 (2009) 232.

[9] M. S. Balathanigaimani, W. G. Shim, C. Kim, J. W. Lee, H. Moon, Surf. Interface Anal., 41 (2009) 484.

[10] J. H. Zhou, Z. J. Sui, J. Zhu, P. Li, D. Chen, Y. C. Dai, W. K. Yuan, Carbon, 45 (2007) 785

[11] G. S.Vicente, P. A. Fernando, D. V. Carlos Javier, P. V. Jose, Carbon, 37 (1999) 1517

[12] M. A. Natal-Santiago, J. M. Hill, J.A. Dumesic, J. Molecular. Catalysis A. Chemical., 140 (1999) 199

[13] A. S. Mestre, J. Piresm, J. M. F. Nogueira, B. J. Parra, A. P. Carvalho, C. O. Ania, Bioresour. Technol., 100 (2009) 1720 
[14] N.N. Avgul, and A. V. Kiselev, in “Chemistry and Physics of Carbon” (P. J. Walker, Jr., Ed.). Dekker, New York, 1970.

[15] M. Heuchel, M. Jaroniec, and R. K. Glipin, Langmuir, 9 (1993) 2573

[16] J. Choma, and M. Jaroniec, Langmuir, 13 (1997) 1026

[17] M Jaroniec, and J. Choma, Mater. Chem. Phys., 19 (1988) 267

[18] P. Podkoscienly, A. Dabrowski, and O. V. Marijuk, Appl. Surf. Sci., 205 (2003) 297

[19] A. W. Harding, N. J. Foley, P. R. Norman, D. C. Francis, and K. M. Thomas, Langmuir, 14 (1998) 3858

[20] W.H. Lee, P.J. Reucroft, Carbon, 37 (1999) 7 
Table 1. Physical properties of ACs

\begin{tabular}{ccccc}
\hline Sample & ${ }^{\mathrm{a}} \mathrm{S}_{\mathrm{BET}}$ & \multicolumn{4}{c}{ Pore volume $\left(\mathrm{cm}^{3} / \mathrm{g}\right)$} & ${ }^{\mathrm{b}}$ A.P.W \\
\cline { 2 - 5 } & $\mathrm{m}^{2} / \mathrm{g}$ & $\mathrm{V}_{\mathrm{DR}}$ & $\mathrm{V}_{\mathrm{DFT}}$ & $\mathrm{nm}$ \\
\hline $\mathrm{R}-1 / 2$ & 2269 & 0.94 & 1.03 & 1.07 \\
$\mathrm{R}-1 / 4$ & 3199 & 1.69 & 1.65 & 1.41 \\
$\mathrm{WAC}$ & 882 & 0.58 & 0.47 & 2.62 \\
\hline
\end{tabular}

${ }^{a}$ BET : Specific surface area (relative pressure range: $0.01-0.05$ )

${ }^{b}$ Average pore width 
Table 2. Distribution of oxygen containing groups on ACs determined by XPS

\begin{tabular}{cccccc}
\hline Sample & \multicolumn{5}{c}{$\mathrm{C} 1 \mathrm{~s}$} \\
\cline { 2 - 6 } & ${ }^{\mathrm{a}} \mathrm{G} . \mathrm{C}(\%)$ & $\mathrm{C}-\mathrm{O}-(\%)$ & $\mathrm{C}=\mathrm{O}(\%)$ & $\mathrm{O}-\mathrm{C}=\mathrm{O}(\%)$ & Carbonate (\%) \\
\hline $\mathrm{R}-1 / 2$ & 80.55 & 12.85 & -- & 6.59 & -- \\
$\mathrm{R}-1 / 4$ & 68.15 & 8.02 & 10.28 & 7.22 & 6.33 \\
$\mathrm{WAC}$ & 65.09 & 13.13 & 3.8 & 3.38 & 3.43 \\
\hline
\end{tabular}

${ }^{\text {a }}$ Graphitic carbon 
Table 3. Adsorption equilibrium parameters of acetaldehyde on ACs

\begin{tabular}{cccccccc}
\hline Sample & \multicolumn{3}{c}{ Langmuir } & \multicolumn{5}{c}{ Freundlich } \\
\cline { 2 - 7 } & $\begin{array}{c}\mathrm{q}_{\mathrm{m}} \\
(\mathrm{mmol} / \mathrm{g})\end{array}$ & $\begin{array}{c}\mathrm{b} \\
(\mathrm{L} / \mathrm{mmol})\end{array}$ & $\mathrm{R}^{2}$ & $\begin{array}{c}\mathrm{K}_{\mathrm{Fr}} \\
(\mathrm{mol} / \mathrm{g})(\mathrm{mmol} / \mathrm{L})^{\mathrm{n}}\end{array}$ & $\mathrm{n}$ & $\mathrm{R}^{2}$ \\
\hline $\mathrm{R}-1 / 2$ & 1.12 & 0.028 & 0.99 & 0.044 & 1.53 & 0.96 \\
$\mathrm{R}-1 / 4$ & 1.08 & 0.012 & 0.99 & 0.017 & 1.26 & 0.98 \\
WAC & 0.88 & 0.02 & 0.98 & 0.031 & 1.51 & 0.99 \\
\hline
\end{tabular}


Table 4. Parameters of adsorption kinetics of acetaldehyde on ACs at room temperature

\begin{tabular}{|c|c|c|c|c|c|c|c|}
\hline \multirow[t]{2}{*}{ Sample } & \multirow[b]{2}{*}{$\begin{array}{c}\mathrm{C}_{0} \\
(\mu \mathrm{mol} / \mathrm{L})\end{array}$} & \multicolumn{3}{|c|}{ Pseudo first-order model } & \multicolumn{3}{|c|}{ Pseudo second-order model } \\
\hline & & $\begin{array}{c}\mathrm{q}_{\mathrm{e}} \\
(\mu \mathrm{mol} / \mathrm{g})\end{array}$ & $\begin{array}{c}\mathrm{k}_{\mathrm{f}} \\
(\mu \mathrm{mol} / \mathrm{g} \cdot \mathrm{min})\end{array}$ & $\mathrm{R}^{2}$ & $\begin{array}{c}\mathrm{q}_{\mathrm{e}} \\
(\mu \mathrm{mol} / \mathrm{g})\end{array}$ & $\begin{array}{c}\mathrm{k}_{\mathrm{s}} \\
(\mu \mathrm{mol} / \mathrm{g} \cdot \mathrm{min})\end{array}$ & $\mathrm{R}^{2}$ \\
\hline \multirow{4}{*}{$\mathrm{R}-1 / 2$} & 10.7 & 4.8 & 7.0 & 0.80 & 59.5 & $4.5 * 10^{-3}$ & 0.99 \\
\hline & 42.8 & 12.3 & 4.9 & 0.80 & 277.8 & $9.2 * 10^{-4}$ & 0.99 \\
\hline & 85.6 & 12.7 & 6.2 & 0.98 & 434.8 & $6.7^{*} 10^{-4}$ & 0.99 \\
\hline & 107 & 15.0 & 5.3 & 0.94 & 588.2 & $6.6 * 10^{-4}$ & 0.99 \\
\hline \multirow{4}{*}{$\mathrm{R}-1 / 4$} & 10.7 & 3.5 & 10.8 & 0.97 & 42.6 & $7.7 * 10^{-3}$ & 0.99 \\
\hline & 42.8 & 8.6 & 6.6 & 0.84 & 196.1 & $1.6^{*} 10^{-3}$ & 0.99 \\
\hline & 85.6 & 11.1 & 8.1 & 0.90 & 370.4 & $8.4 * 10^{-4}$ & 0.99 \\
\hline & 107 & 10.9 & 8.4 & 0.89 & 400.0 & $9.2 * 10^{-4}$ & 0.99 \\
\hline \multirow{4}{*}{ WAC } & 10.7 & 3.4 & 8.4 & 0.70 & 62.9 & $6.7 * 10^{-3}$ & 0.99 \\
\hline & 42.8 & 9.0 & 7.2 & 0.94 & 222.2 & $1.5^{*} 10^{-3}$ & 0.99 \\
\hline & 85.6 & 10.8 & 8.2 & 0.86 & 344.8 & $7.8 * 10^{-4}$ & 0.99 \\
\hline & 107 & 11.6 & 7.5 & 0.91 & 416.7 & $8.6 * 10^{-4}$ & 0.99 \\
\hline
\end{tabular}




\section{Figures Captions}

Fig. 1. The DFT pore size distributions of ACs

Fig. 2. FT-IR spectra of all the ACs in the range of $4000-1000 \mathrm{~cm}^{-1}$

Fig. 3. XPS spectra of all the ACs (1) Graphitic; (2) $\mathrm{C}-\mathrm{OH}, \mathrm{C}-\mathrm{O}-\mathrm{C}$; (3) $\mathrm{C}=\mathrm{O}$; (4) $\mathrm{C}=\mathrm{OOR}$; (5) Carbonate

Fig. 4. Adsorption equilibrium isotherms of acetaldehyde on ACs at room temperature Fig. 5. Adsorption energy distributions of acetaldehyde on ACs at room temperature Fig. 6. The adsorption isotherms of water vapor on ACs

Fig. 7. Pseudo second-order kinetics on ACs by varying the initial acetaldehyde concentrations at room temperature ((०) $107 \mu \mathrm{mol} / \mathrm{L}$. ( $\quad 85) 6 \mu \mathrm{mol} / \mathrm{L}$. ( $\quad 42.8 \mu \mathrm{mol} / \mathrm{L}$. $(\diamond) 10.7 \mu \mathrm{mol} / \mathrm{L})$ 

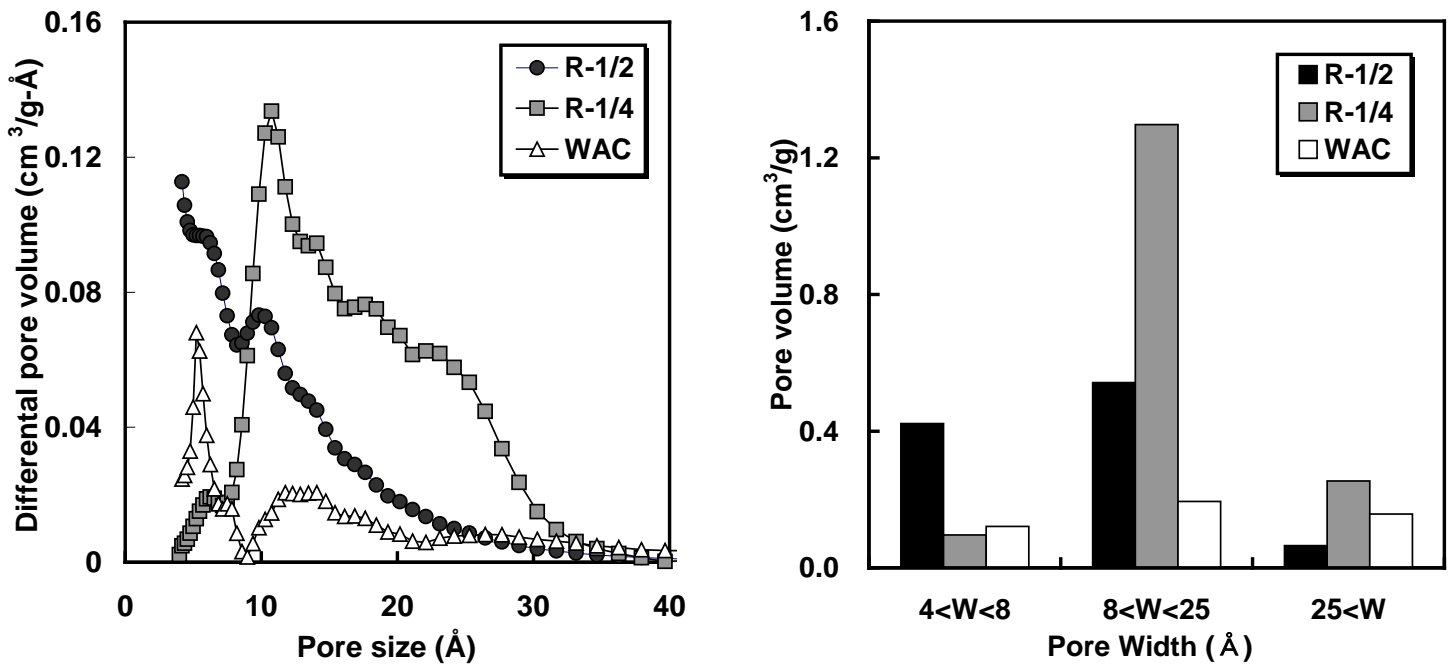

Fig. 1. The DFT pore size distributions of ACs 


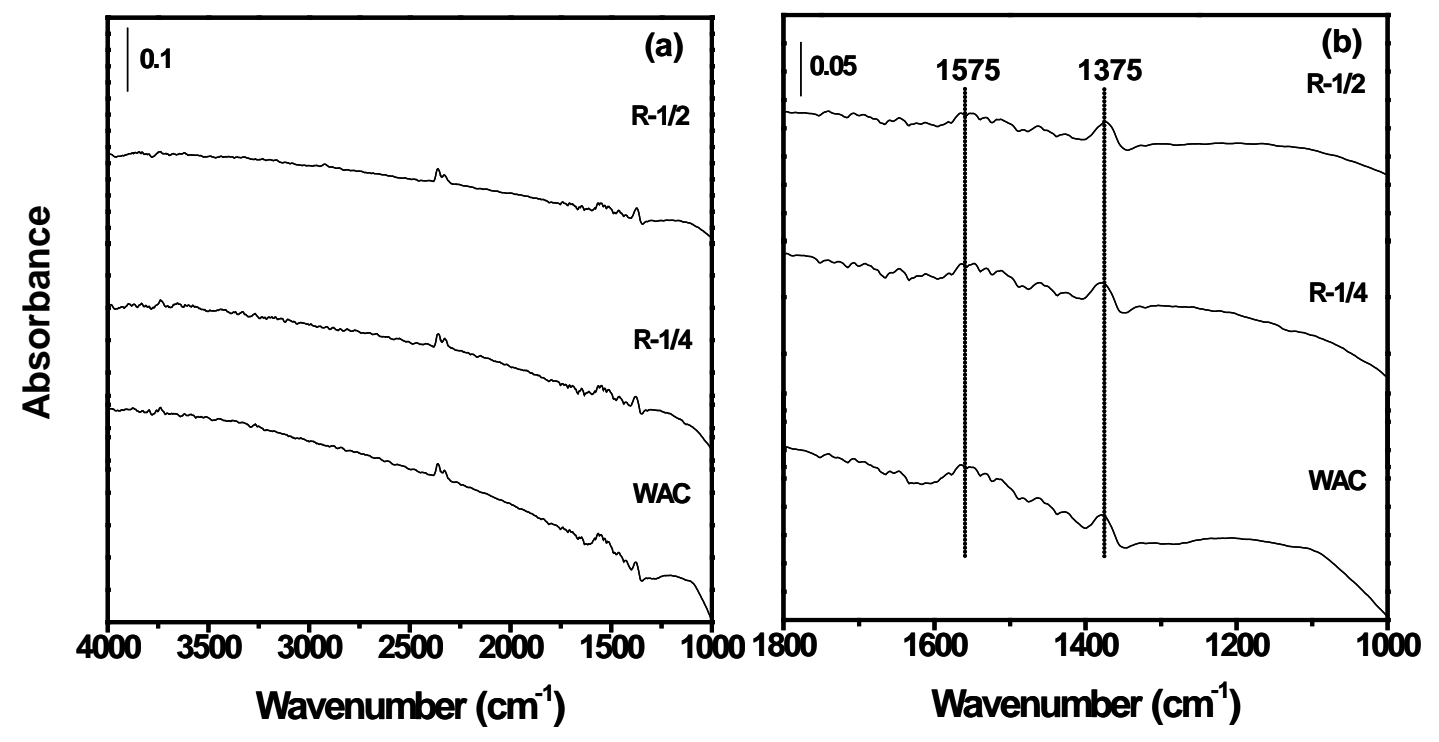

Fig. 2. FT-IR spectra of ACs in the range of $4000-1000 \mathrm{~cm}^{-1}$ 

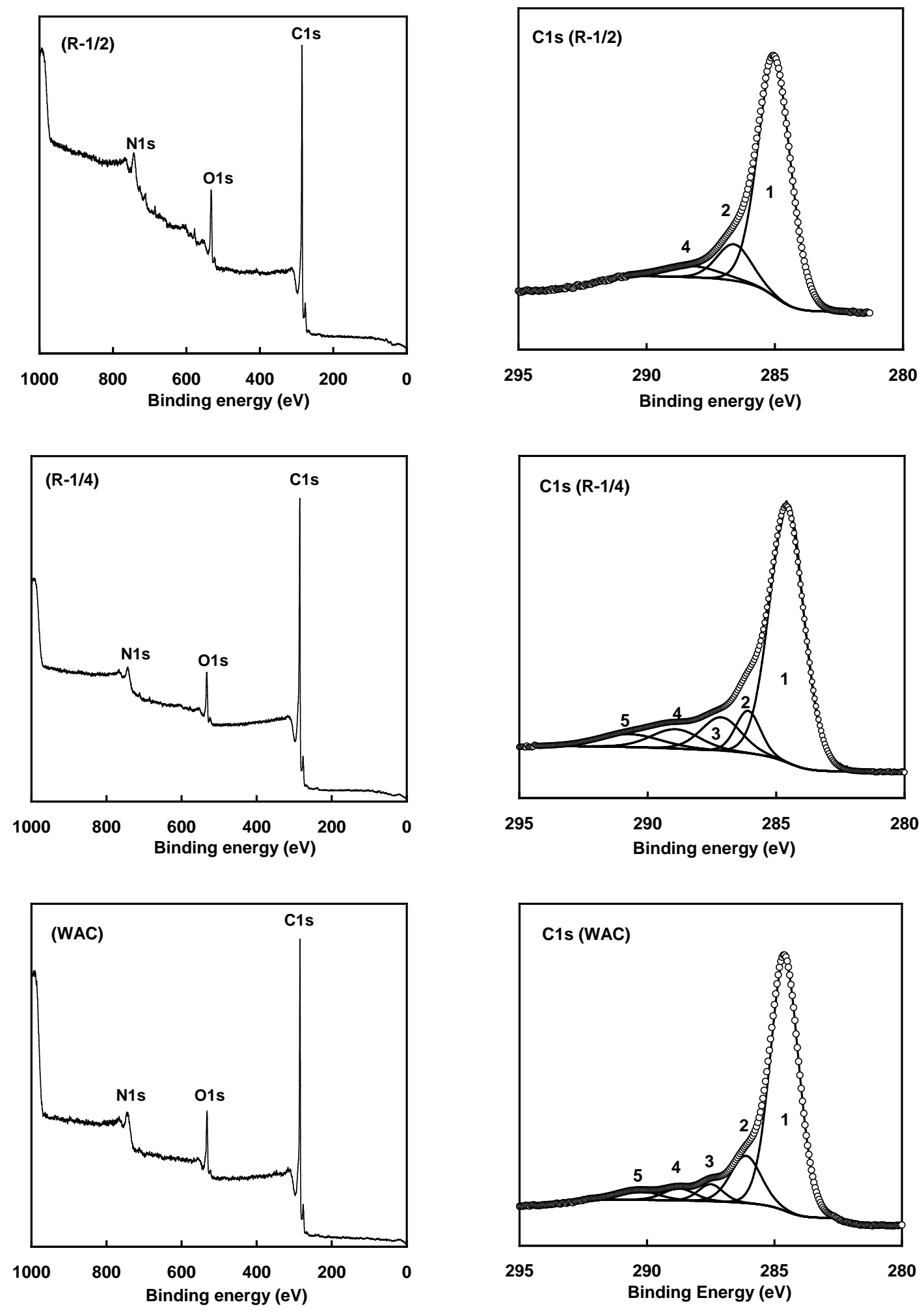

Fig. 3. XPS spectra of ACs (1) Graphitic; (2) $\mathrm{C}-\mathrm{OH}, \mathrm{C}-\mathrm{O}-\mathrm{C}$; (3) $\mathrm{C}=\mathrm{O}$; (4) $\mathrm{C}=\mathrm{OOR}$; (5) Carbonate 


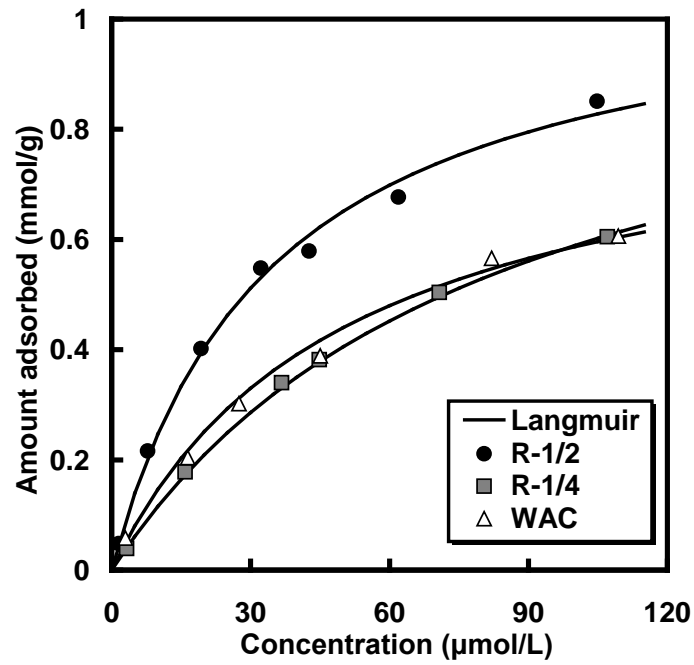

Fig. 4. Adsorption equilibrium isotherms of acetaldehyde on ACs at room temperature 


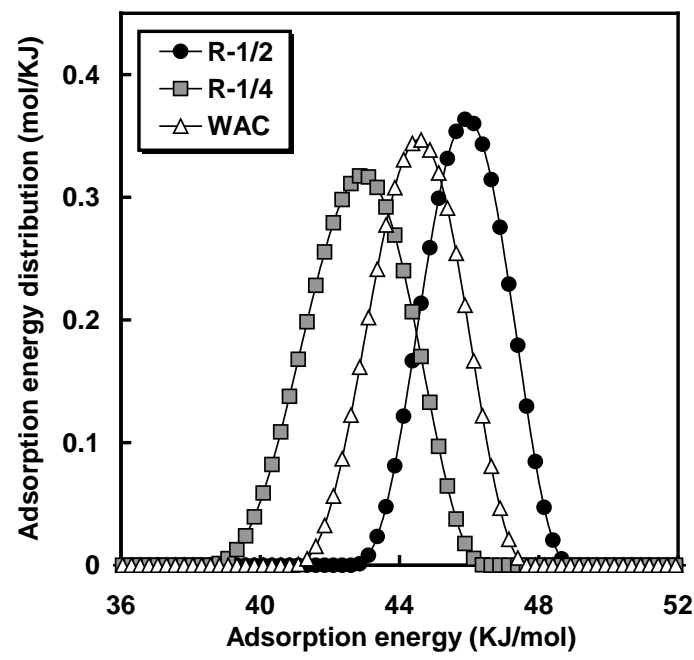

Fig. 5. Adsorption energy distributions of acetaldehyde on ACs at room temperature 


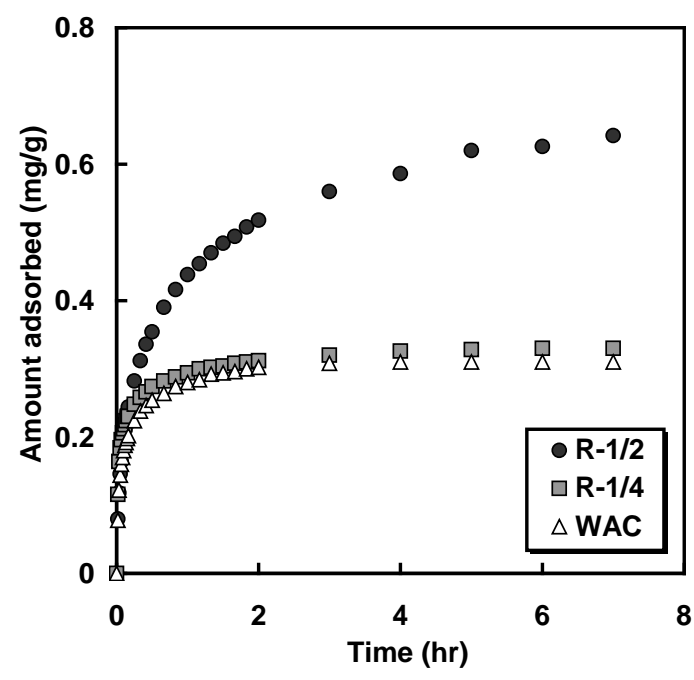

Fig. 6. The adsorption isotherms of water vapor on ACs 

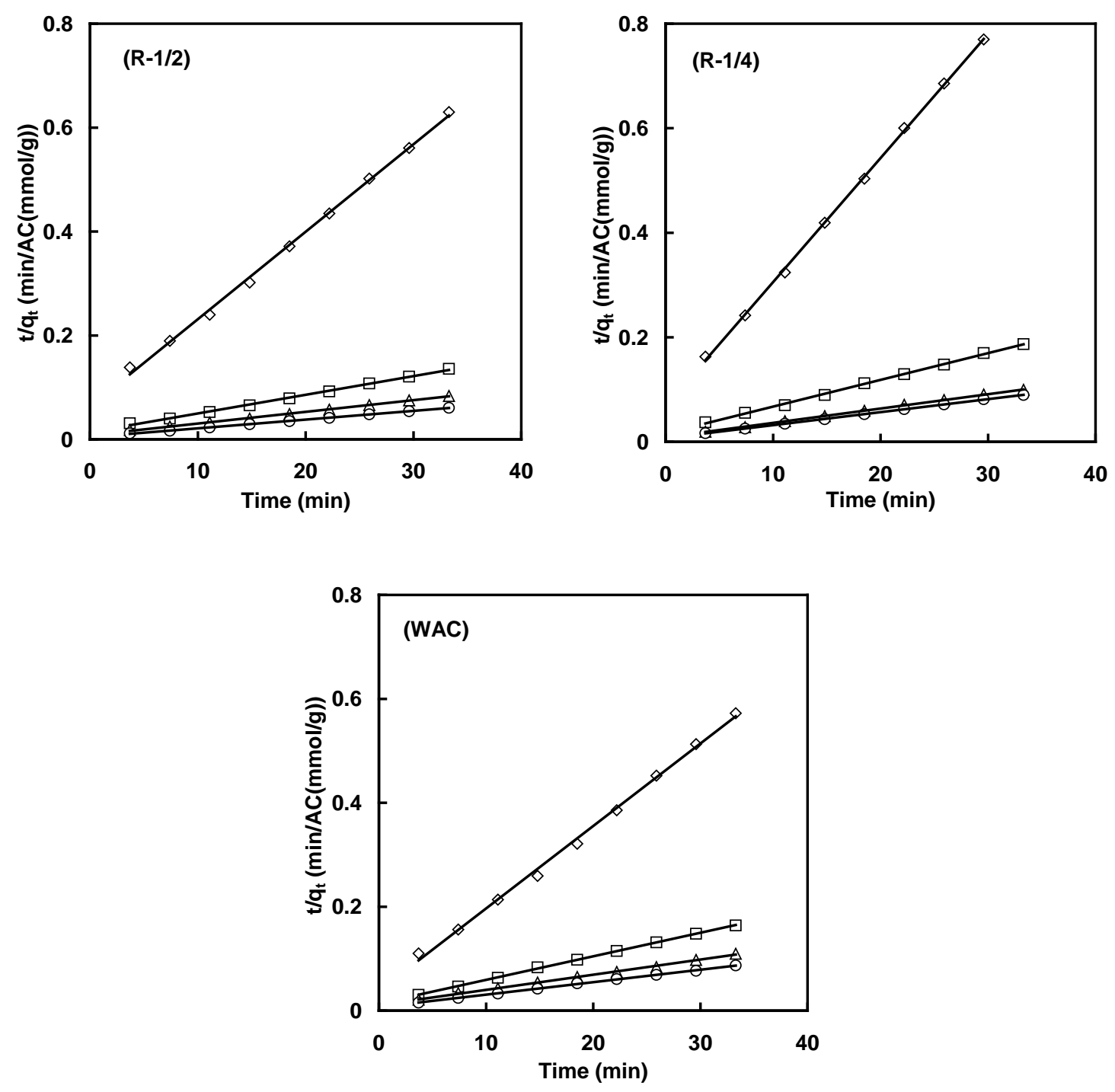

Fig. 7. Pseudo second-order kinetics on ACs by varying the initial acetaldehyde concentrations at room temperature ( $\circ 107 \mu \mathrm{mol} / \mathrm{L}, \Delta 85.6 \mu \mathrm{mol} / \mathrm{L}, \square 42.8 \mu \mathrm{mol} / \mathrm{L}, \diamond$ $10.7 \mu \mathrm{mol} / \mathrm{L}$ ) 